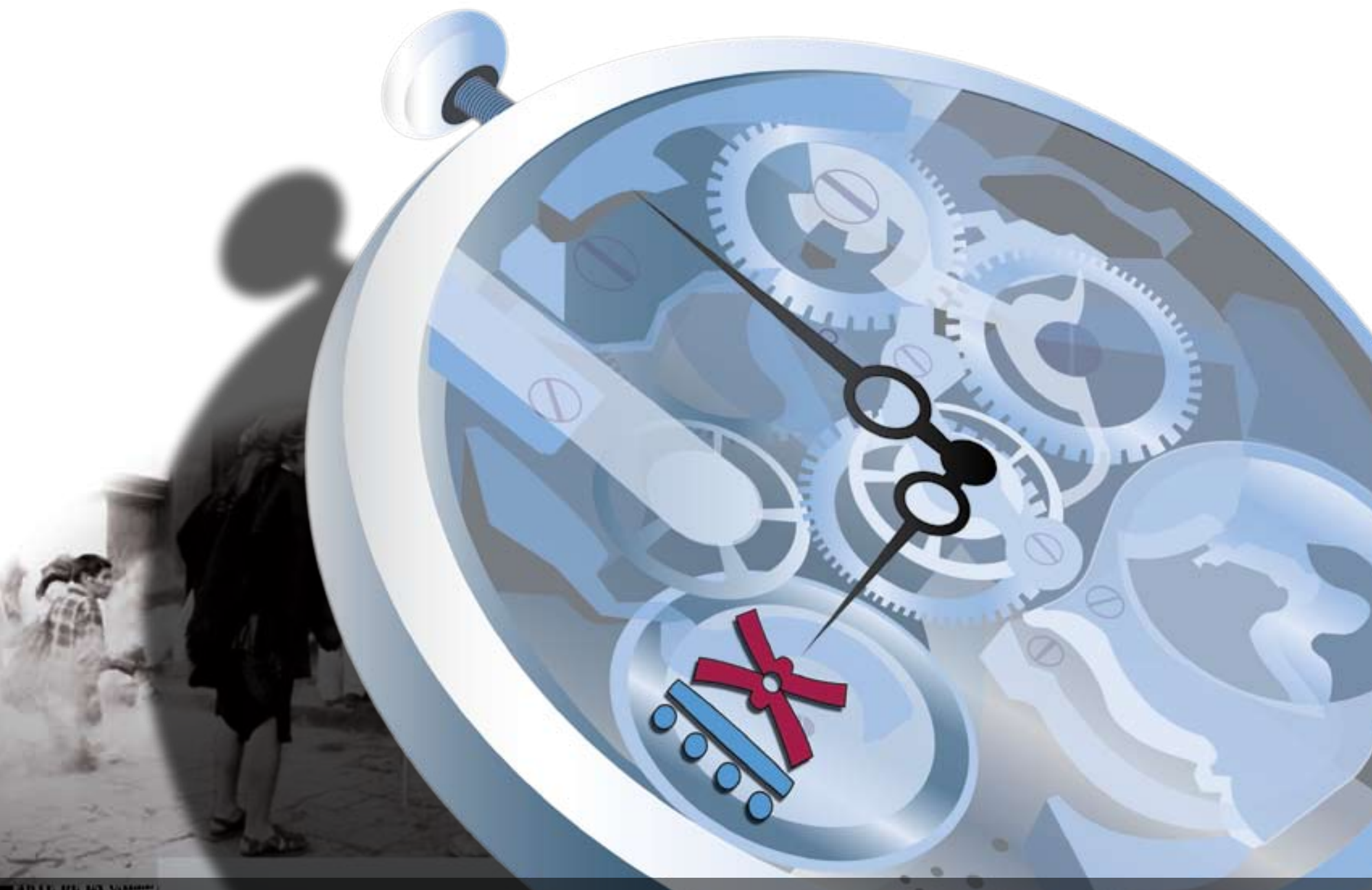

$9^{\circ}$ C O N G R E S O 2. CENTROAMERICANO DE H ISTO R I A

Universidad de Costa Rica ISSN 1409- 469X

Fecha de recepción: 15 de mayo 2008 Fecha de aceptación: 30 de mayo 2008

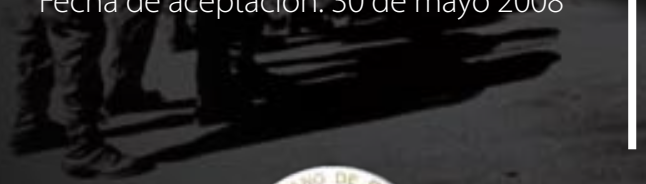

LOS ORÍGENES DEL PREDOMINIO MILITAR EN LOS SISTEMAS POLÍTICOS SALVADOREÑO Y HONDUREÑO

Miembros del Consejo Editorial:

Dr. Ronny Viales, Dr. Juan José Marín

Editores Técnicos:

Allan Fonseca, Andrés Cruz, Gabriela Soto
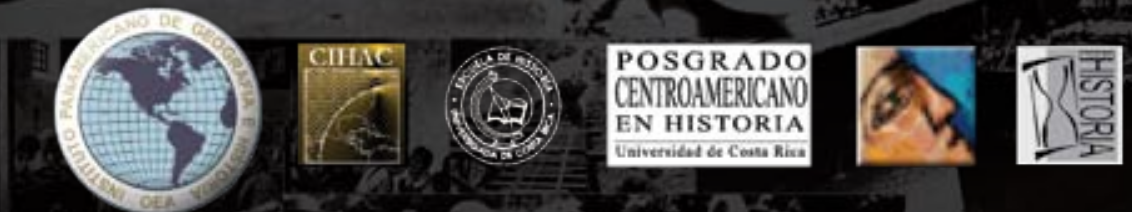
Indexaciones: Repositorio de Revistas UCR, DIALNET, Latindex, REDALYC Directorio y recolector de recursos digitales del Ministerio de Cultura de España, Directory of Open Access Journals.

\title{
LOS ORÍGENES DEL
} PREDOMINIO MILITAR EN

\section{LOS SISTEMAS POLÍTICOS} SALVADOREÑO Y HONDUREÑO

\author{
Carlos Pérez Pineda
}

\begin{abstract}
El autor del presente ensayo es egresado de la Maestría de Historia de Centroamérica en el Postgrado Centroamericano de Historia de la Universidad de Costa Rica y actualmente investiga sobre el conflicto Honduras-El Salvador como tema de tesis. Dirección electrónica: gualcho2002@yahoo.com
\end{abstract}


Elpresentedocumento estádedicadoa explicarbrevemente elorigenhistóricodeldesproporcionado protagonismo de los militares hondureños y salvadoreños en los procesos políticos de sus respectivos países. La explicación del origen de los patrones divergentes de desarrollo político en ambos países haciendo énfasis en el rol de las fuerzas armadas es una premisa para una mejor comprensión de la naturaleza de los regímenes políticos dominados por los militares durante el siglo XX. Algunos autores sostienen que los orígenes de la relación histórica entre las clases propietarias y las Fuerzas Armadas deben buscarse en los procesos de consolidación estatal ${ }^{1}$. La transición de un estado patrimonial dominado por caudillos militares a un estado centralizado y moderno constituyó un largo proceso plagado de una violenta inestabilidad política y marcado por el fracaso de repetidos intentos de reforma militar. El estado burocrático moderno, capaz de ejercer efectivamente su autoridad sobre su población en la totalidad del territorio nacional fundamentalmente a través del control de los medios de violencia, es un fenómeno relativamente tardío que no manifiesta su presencia plena hasta el siglo XX en la mayoría de los países centroamericanos.

\section{LA INTERPRETACIÓN PATH-DEPENDENCE}

Parece existir un consenso entre los estudiosos de las sociedades del istmo centroamericano acerca de la necesidad de estudiar el período comprendido entre las décadas de 1870 y 1930 para poder comprender la historia de la región durante el siglo XX. El modelo teórico-interpretativo para el análisis del desarrollo histórico social en el largo plazo propuesto por James Mahoney², conocido como path dependence, proporciona una explicación de los orígenes del moderno régimen militar-autoritario salvadoreño y del régimen de dictadura tradicional en Honduras a partir de las transformaciones iniciadas durante el período de reforma liberal de finales del siglo XIX. Las diferencias esenciales de las instituciones estatales y las relaciones de clase así como la trayectoria contrastante de los cambios de régimen político en los países centroamericanos solamente pueden ser comprendidas cabalmente a partir de una perspectiva comparativa de los procesos reformistas liberales, considerados como coyunturas críticas, de sus secuencias reactivas y de los regímenes resultantes. Las diversas opciones políticas de los liberales centroamericanos en el último cuarto

1 Varas, Augusto. Militarization and the Internacional Arms Race in Latin América. Fotocopia s.f., pp.

7-8.

2 Mahoney, James. Path-Dependent Explanations of Regime Change: Central America in Comparative

Perspective. Studies in Comparative International Development, Spring 2001, Vol. 36, No. 1, pp. 111-141 
del siglo XIX pusieron en movimiento procesos que culminaron en la formación de diferentes regímenes políticos en los países de la región. Mientras Guatemala, El Salvador y Costa Rica constituían, al finalizar el período de reforma en la década de 1920, ejemplos exitosos de reformas liberales de tipo radical en los dos primeros casos y de tipo reformista en el último, las experiencias hondureña y nicaragüense representan dos variantes de liberalismo abortado por fuerzas de origen externo. Mahoney sostiene que opciones políticas radicales aparecieron en países en los que los gobernantes habían construido poderosos establecimientos militares para contrarrestar amenazas políticas. Importantes reformas en materia de política agraria pudieron implementarse una vez que los liberales salvadoreños contaron con el necesario aparato coercitivo construido mediante reformas militares. Los liberales hondureños optaron, por el contrario, por una modesta política de reforma agraria debido a que carecían de una fuerza militar permanente, capaz de irradiar su poder sobre toda la sociedad, que les hubiera permitido optar por una transformación más radical. Mientras el presidente Rafael Zaldívar en El Salvador, amenazado por liberales disidentes dentro y fuera del país, organizó el primer ejército permanente en la historia de la república en 1876, es decir antes de emprender la abolición de todo el sistema de tierras comunales, el presidente hondureño Marco Aurelio Soto, en un ambiente político caracterizado por una ausencia relativa de amenazas políticas, no intentó nunca organizar una fuerza militar permanente limitándose a reorganizar y a expandir las milicias. Mahoney argumenta que en Honduras casi no existió durante el siglo XIX la división tradicional entre liberales y conservadores y que en realidad el período liberal era el resultado de la imposición de Soto por el gobernante guatemalteco Justo Rufino Barrios. El gobierno liberal hondureño libre de la amenaza de enemigos poderosos no consideró necesario modernizar sus fuerzas militares y decidió realizar una política reformista en el sector agrícola en lugar de emprender una transformación de tipo radical como en el vecino El Salvador ${ }^{3}$. Sin embargo, el experimento político reformista de los liberales hondureños fue abortado por la intervención económica de los Estados Unidos bajo la forma de una masiva inversión de capital que derivó en el control externo de la economía bananera y la pérdida parcial de la soberanía nacional ${ }^{4}$. La opción radical en El Salvador y la reformista abortada en Honduras provocaron "reacciones y contrareacciones contrastantes" que derivaron en regímenes políticos diferentes. Esos dos modelos de reforma liberal determinaron la formación de instituciones estatales y estructuras de clase que persistieron durante un largo período de tiempo en ambos 3 Mahoney, James. Path-Dependent Explanations..., p. 121

4 Mahoney, J. Op.Cit., p. 124 
países 5 . A diferencia de la experiencia salvadoreña en donde una oligarquía cafetalera centralizó el poder económico y político, en Honduras existió una bifurcación entre el poder económico y el poder político encarnado por un lado en los grupos de comerciantes establecidos en la ciudad norteña de San Pedro Sula y por otro lado en una elite política concentrada en la ciudad capital, Tegucigalpa. La clase económica dominante hondureña no disponía de las dos fuentes tradicionales de poder de las elites económicas centroamericanas, especialmente la guatemalteca, salvadoreña y costarricense, el control sobre la tierra y la influencia predominante en la política nacional. Mientras el patrón previo de rebeliones armadas regionales en El Salvador había finalizado, en Honduras las revueltas armadas regionales persistieron hasta bien entrado el siglo XX debido al fracasado intento de consolidar el estado durante el período reformista liberal. El aparato estatal salvadoreño relativamente centralizado contaba con el monopolio efectivo de la fuerza organizada al finalizar el período de reforma liberal. Mahoney afirma que la existencia de organizaciones militares modernas a finales del siglo XIX y principios del XX en Guatemala y El Salvador estaba asociada a una economía rural polarizada en ambos países. El autor subraya la intensa polarización de clase del sistema agrícola y el alto potencial de rebelión del campesinado salvadoreño y llama la atención sobre la creación de la Guardia Nacional en 1912 "en parte como una respuesta a esta situación”. La gran influencia ejercida por la oligarquía cafetalera salvadoreña en el estado nacional limitaba además el protagonismo de los sectores subordinados en la escena política. En Honduras, los sectores populares no tuvieron un objetivo hacia el cual dirigir sus aspiraciones democráticas debido a la inexistencia de un estado centralizado y de una elite económica claramente visible ejerciendo el control de la política nacional7 ${ }^{7}$. La cuestión de la democracia participativa fue llevada a la escena política bajo la forma de demandas de mayor igualdad socioeconómica y de mayor libertad electoral durante períodos que Mahoney denomina episodios democratizadores, los cuales deben ser comprendidos como secuencias reactivas a las opciones políticas reformistas. Mientras en Honduras el autoritarismo tradicional no fue nunca

$5 \quad$ Mahoney, pp. 124-125

6 Mahoney, J.., p. 123

$7 \quad$ La movilización laboral y las protestas sociales de la época fueron dirigidas contra compañías extranjeras y no contra políticos y capitalistas locales. Mahoney observa que sin la presencia de movimientos democratizadores Honduras desarrolló formas tradicionales de autoritarismo. Mahoney, p. 126. Otros estudiosos de la historia política de la región han llamada la atención sobre la escasa importancia de los conflictos interclasistas en Honduras destacando que la inestabilidad política del país "no tuvo los orígenes tradicionales por la tierra o el control del mercado de trabajo”. Torres Rivas, E. La piel de Centroamérica. (Una visión epidérmica de setenta y cinco años de su historia). FLACSO. San José, Costa Rica, 2007, p. 41 
interrumpido por episodios democratizadores durante las décadas de 1920 y 1930, en El Salvador los esfuerzos reformistas del presidente Pío Romero Bosque (1927-1931) constituyeron un importante episodio democrático que fue interrumpido por los militares. Mahoney sostiene que los conflictos y luchas políticas entre diversos grupos son esenciales para entender los patrones de cambio de régimen político e insiste en la problemática de las secuencias reactivas detonadas por los diferentes tipos de liberalismo adoptados por las elites. Las diversas opciones políticas de los liberales produjeron diferentes tipos de regímenes políticos, autoritarismo militar en El Salvador y Guatemala, dictadura tradicional en Honduras y Nicaragua y democracia en Costa Rica. Los regímenes políticos resultantes son comprendidos en las explicaciones basadas en el modelo path-dependence como estadios de equilibrio derivados de períodos de transición muy dinámicos ${ }^{8}$.

\section{LAS INSUFICIENCIAS DEL MODELO}

A pesar del reconocimiento de contingencias relativas en las coyunturas críticas, el determinismo es el elemento central en el modelo de análisis path-dependence y la explicación del autoritarismo militar del siglo XX por la existencia de una estructura económica polarizada persistente en el campo derivada de decisiones de la elite liberal para modernizar la economía y el estado es, además de determinista, muy discutible considerando los resultados de importantes investigaciones basadas en el análisis de una sólida base documental. Las coyunturas críticas de finales del siglo XIX no produjeron resultados inmediatos plenamente conformados sino que pusieron en movimiento procesos desiguales que alcanzaron su total desarrollo a finales de la década de 1920 y principios de la de 1930. El modelo path-dependence puede ser criticado por su enfoque elitista y reduccionista que presupone a miembros de la elite liberal eligiendo racionalmente una entre varias opciones presentes en una determinada coyuntura crítica. La investigación sobre el campesinado salvadoreño del siglo XIX realizada por Aldo Lauria-Santiago cuestiona las supuestas intenciones radicales de los reformistas liberales. Lauria-Santiago afirma que "Ia decisión de privatizar las tierras tuvo múltiples orígenes y motivaciones; no se proponía destruir la tenencia campesina de la tierra, sino consolidarla y orientarla hacia la economía de mercado. De modo similar, los resultados de la privatización fueron complejos y permitieron la titulación de tierras por parte de campesinos y labradores como también de empresarios urbanos" ${ }^{\text {. }}$. Si 8 Mahoney, p. 136.

9 Lauria-Santiago, Aldo A. Una república agraria. Los campesinos en la economía y la política de EI 
bien es cierto que algunas de las consecuencias más directas de la reforma liberal -como la pérdida de poder y protagonismo de las municipalidades y las comunidades étnicas- fueron radicales, también es cierto que la reforma agraria liberal, a pesar de acarrear nuevos conflictos y contradicciones, resolvió muchos problemas no solamente de los grandes cafetaleros sino también de lo que Lauria-Santiago denomina una clase media rural emergente integrada por comerciantes y “campesinos emprendedores" dedicados a la agricultura comercial. Esa nueva clase media rural era la opositora principal del sistema de tierras comunes y contaba inclusive con un medio para publicar sus opiniones, el Boletín de Agricultura ${ }^{10}$. En la década de 1880 el estado actuó presionado por la progresiva comercialización de la agricultura e intentó resolver mediante la privatización de las tierras comunes las contradicciones y los dilemas generados por la persistencia de los sistemas de tierras ejidales y comunales. La decisión "radical” tuvo diversas motivaciones y no se originó únicamente en los círculos de la elite cafetalera. Lauria-Santiago subraya que los argumentos del gobierno de la república para justificar la abolición de las comunidades propietarias de tierras eran en gran medida correctas ya que grandes extensiones de tierra que permanecían incultas y el control comunal de la tierra desalentaba a campesinos y agricultores comerciales para emprender la siembra de cultivos de largo plazo como café, cacao y caucho. Las comunidades estaban divididas por conflictos internos entre sus miembros y mantenían conflictos con personas ajenas a las mismas que, según Lauria-Santiago, amenazaban al orden público. Muchos de los principales usuarios de tierras ejidales eran opositores del sistema de tierras comunes debido a dos razones fundamentales: la creciente diferenciación social entre los campesinos y la participación de "agricultores de vocación empresarial" en el sistema de ejidos ${ }^{11}$. Las intenciones específicas del gobierno al promover la privatización de las tierras comunes no fueron muy claras y, según Lauria-Santiago, existen pocos documentos que describen la manera en que se creó la legislación para ejecutar dicha privatización. El autor insiste, sin embargo, en que el objetivo del gobierno no era separar al campesinado de su principal medio de subsistencia sino crear una clase campesina empresarial capaz de impulsar el desarrollo agrícola del país y, de modo especial, el del sector orientado a la exportación. El resultado de la reforma liberal fue muy contradictorio pero no produjo una estructura agraria polarizada en el Salvador en el siglo XIX. Dirección de Publicaciones e Impresos. Consejo Nacional para la Cultura y el Arte, CONCULTURA. San Salvador, El Salvador, 2003, pp. 253-254. Aldo Lauria-Santiago fue el primer investigador académico que utilizó ampliamente los archivos de El Salvador

10 Lauria-Santiago, A. Una república agraria..., pp. 255-256

11 Lauria-Santiago, pp. 258-259 
corto plazo ${ }^{12}$. Los derechos de propiedad fueron transferidos masivamente a campesinos y pequeños agricultores en su mayor parte, "pero también a la emergente elite empresarial, especialmente mediante subasta o venta de extensiones de tierra ociosa a inversionistas comerciales, hacendados y especuladores”"13. Hubo casos de corrupción y abuso, sobre todo de parte de autoridades municipales, pero, en general, "funcionarios nacionales vigilaron estrechamente el proceso de titulación y las quejas de los afectados por procedimientos corruptos fueron escuchadas" ${ }^{14}$. En contra de las interpretaciones de la mayoría de los estudiosos del tema, Lauria-Santiago sostiene que los conflictos asociados con la privatización de las tierras comunes fueron muy variados y que la elite terrateniente no arrebató las tierras de los campesinos mediante la fuerza. Los campesinos pudieron, generalmente, titular sus tierras y el proceso de reforma creó un campesinado que tenía control sobre sus tierras pero que concurrió desventajosamente en la reclamación de tierras ociosas adicionales restringiendo las posibilidades de expansión de las futuras generaciones de campesinos. El proceso de reforma liberal produjo un campesinado propietario privado de su tierra pero, al mismo tiempo,"abrió las puertas al eventual empobrecimiento de muchos otros y, ciertamente, conllevó el potencial de la proletarización o de poblaciones sin acceso a tierras" ${ }^{15}$. Los campesinos que, por causas diversas, no denunciaron ejidos, tierras comunales y baldíos se convirtieron en colonos o asalariados a tiempo completo ${ }^{16}$. La reforma agraria liberal no produjo una estructura agraria de clases polarizada en el siglo XIX pero puso en movimiento procesos tendientes a dicha polarización que culminaron en la década de 1920. La presión sobre grandes grupos de trabajadores rurales y campesinos a mediados de dicha década produjo un descontento que favoreció el surgimiento de sindicatos de trabajadores y nuevos reagrupamientos políticos durante los gobiernos de Romero Bosque y Araujo. La reforma liberal salvadoreña es indudablemente un importante episodio de la historia salvadoreña pero el carácter de encrucijada histórica que se le ha atribuido debe ser reexaminado a la luz de lo que revela la documentación de los archivos nacionales. Lauria-Santiago observa que "la llamada revolución liberal de 1871 en El Salvador no fue una ruptura abrupta de las políticas 12 El ritmo de la división y privatización de las tierras comunales fue desigual. Mientras en ciertos lugares fue un proceso relativamente rápido, en otros “donde la tradición local o la resistencia de la comunidad retrasó la reforma de las costumbres existentes" generalmente tardó "unos veinticinco años, plagados de conflictos" y algunos conflictos sobre linderos se extendieron inclusive hasta el siglo XX. Lauria-Santiago, pp. 268-269

13 Lauria-Santiago, p. 285

14 Lauria-Santiago, p. 266

15 Lauria-Santiago, p. 298

16 Ibíd. 
de estado o ideología, ni siquiera del modo de hacer política...Los acontecimientos de 1871 no representan la súbita toma del estado por una clase particular, o por una fracción de clase. Más que otra cosa, fueron un eslabón más de una larga cadena de alianzas e intervenciones en que participaron Guatemala y sus aliados locales, una densa red de luchas y alianzas que ningún historiador ha logrado desenmarañar todavía" ${ }^{17}$. En el caso de Honduras, la economía nacional del período anterior a la década de 1870 no permitía sustentar un fuerte poder estatal centralizador. La ausencia en la historia hondureña de una oligarquía cafetalera nacional capaz de construir un estado nacional se debió a algo más que a la pérdida parcial de soberanía debido al control de la economía bananera por compañías extranjeras. Darío Euraque señala que la elite reformista liberal simplemente no estaba interesada en la alternativa representada por la producción cafetalera debido a las íntimas vinculaciones comerciales de algunos de sus miembros más prominentes con el boom minero. De acuerdo con Euraque, las elites hondureñas inclusive abandonaron las importantes regiones cafetaleras de Santa Bárbara y Comayagua en las décadas de 1880 y 1890 para asentarse en la llamada Costa Norte atraídos por las nuevas oportunidades derivadas de la expansión del cultivo del banano en dicha región. Euraque destaca que la decisión de la elite hondureña tuvo poco que ver con supuestos "impedimentos" asociados con la producción del café, "la elite comercial e incluso agrícola tenía más que ganar del relativamente fácil acceso a las tierras bananeras y de las oportunidades comerciales, que del café. Con el tiempo Honduras no tuvo una oligarquía cafetalera, ni su consiguiente Estado ultra autoritario y exclusivista. En su lugar, la Costa Norte se convirtió en una región fronteriza con una economía y cultura política distintivas" ${ }^{18}$. Euraque critica a una historiografía que descarta demasiado fácilmente a la región caribeña de Honduras, reduciéndola frecuentemente a una enorme plantación bananera propiedad de compañías extranjeras imperialistas y haciendo caso omiso de su compleja historia política, económica y social ${ }^{19}$. La modernización impulsada por la economía bananera estimuló la formación de una burguesía regional y la ciudad de San Pedro Sula se convirtió en el bastión de las fuerzas del reformismo hondureño que, en la segunda mitad del siglo XX, colisionaron inevitablemente con el caudillismo del interior del país representado por Tegucigalpa. A pesar de la modernización regional en la Costa Norte es importante hacer énfasis

17 Lauria-Santiago, pp. 335-336

18 Euraque, Darío. El capitalismo de San Pedro Sula y la historia política hondureña (1870-1972).

Editorial Guaymuras, Tegucigalpa, 2001, pp. 47-49

19 Euraque, Darío. El capitalismo de San Pedro Sula y..., p. 307 
en la incapacidad de Honduras de convertirse, durante el siglo XIX, en una entidad económica exportadora de productos agrícolas. La formación de un sistema económico nacional fue obstaculizada no solamente por las barreras topográficas del país sino también por el evidente fracaso del proyecto para crear una clase de agricultores comerciales dedicada a los cultivos de exportación. José Guevara Escudero observa que "con este fracaso llegó a su fin el ambicioso plan de fomentar el desarrollo económico nacional a través de la exportación de café u otros cultivos comerciales producidos por agricultores locales" ${ }^{20}$. El cultivo del café no logró arraigarse entre los agricultores de las tierras altas, el único espacio geográfico del país donde dicho cultivo pudo haber tenido éxito, y la economía campesina de productos tradicionales continuó integrada a circuitos comerciales regionales que a menudo trascendían las fronteras nacionales. El fracaso de la reforma liberal en Honduras tiene orígenes diversos, internos y externos. Es necesario considerar también la actitud de los grupos sociales subalternos ante la introducción de nuevos cultivos comerciales promovida por los reformistas liberales para explicar el fracaso del experimento reformista en Honduras y no limitar el análisis exclusivamente a lo que sucedía en la esfera de las elites nacionales. Las tierras altas concentraban a la mayor parte de la población hondureña de finales del siglo XIX, mayoritariamente campesinos que sembraban para la subsistencia y el comercio local/regional. Guevara Escudero sostiene que la población hondureña no apoyó los programas de reforma del gobierno liberal y destaca que "el hondureño promedio sospechaba de las intenciones dictatoriales del Estado al tratar de cambiar sus costumbres tradicionales. Además, resentía aún más el adoctrinamiento de las ideas liberales a través del servicio militar obligatorio y no en el aula de clase. El decreto del 4 de octubre de 1878 que creó el servicio militar para los hombres hondureños entre las edades de 18 y 35 años, hizo que la Reforma no fuera muy popular entre los habitantes de las tierras altas, quienes resentían la interferencia foránea en su vida" ${ }^{21}$. Ni la elite ni los campesinos estuvieron interesados en dedicarse al cultivo del café y la carencia de inversión extranjera en ese nuevo sector contribuyó también a su fracaso. Según Guevara Escudero sería, no obstante, equivocado considerar a la reforma liberal de 1877 como un fracaso total debido a que "en el análisis final, la Reforma fue

20 Guevara Escudero, José. Honduras en el siglo XIX: su historia socioeconómica 1839-1914. Fondo Editorial Universidad Pedagógica Nacional Francisco Morazán. Tegucigalpa, Honduras, 2007, pp. 209-210. La importante obra de José Guevara Escudero es el resultado de una investigación acuciosa utilizando más de noventa padrones poblacionales de casi la totalidad de las diferentes regiones del país encontrados por el investigador en el Archivo Nacional de Honduras

21 Guevara Escudero, p. 223 
el vehículo por medio del cual llegaron las inversiones al país para desarrollar los sectores bananeros y mineros de la economía. Esto era crucial para el desarrollo económico del país y como consecuencia de esto, muchos años después al país se le identificó con sólo una de estas exportaciones - el banano"22. El capital extranjero contribuyó al crecimiento de la producción bananera y minera, ejerciendo al mismo tiempo el control de los enclaves desde donde se realizaban la mayor parte de las exportaciones del país a los mercados extranjeros. El aislamiento y el rezago de las poblaciones de las tierras altas aumentaron al canalizarse la inversión extranjera directa a los sectores más dinámicos de la economía. Guevara Escudero subraya que "las inversiones directas también le permitieron a las compañías extranjeras trasladar todas sus ganancias a sus oficinas centrales en el exterior, así debilitando la economía de la nación "23. El "aborto" de la reforma liberal no se debió únicamente a la intervención de fuerzas externas sino a un conjunto de factores internos y externos entre los cuales el control del sector más dinámico de la economía hondureña por el capital norteamericano tuvo un gran impacto en el desarrollo del país durante el siglo XX.

\section{LA CUESTIÓN DEL INTERVENCIONISMO MILITAR EN EL SISTEMA POLÍTICO}

Según Mahoney la viabilidad y durabilidad de un régimen depende del desarrollo del aparato estatal y, especialmente, de la organización de su fuerza militar ${ }^{24}$. La explicación path-dependence subraya la íntima vinculación entre un estado centralizado y la organización de fuerzas militares modernas con el surgimiento de una economía rural polarizada en El Salvador. El monopolio de la fuerza habría permitido la subordinación violenta de los campesinos despojados de sus tierras por la reforma agraria liberal impulsada por el presidente Zaldívar. El problema de la centralización del estado y su monopolio sobre los medios de coerción debe ser examinado con mayor penetración cuestionando en el camino algunas de las simplificaciones más persistentes de la historia política centroamericana. Considerando la vigencia, dentro y fuera de los ámbitos académicos, de una visión mítica del pasado histórico salvadoreño influenciada, por lo menos parcialmente, por supuestos teóricos elaborados sobre una base empírica muy reducida durante el período de polarización y radicalización ideológica característico de la crisis política de la

$22 \quad$ Ídem

23 Guevara Escudero, p. 266

24 Ibid 
década de $1970^{25}$, es necesario reexaminar procesos cruciales, como el supuesto repliegue oligárquico después de una fantasmagórica decisión de gobernar a través del ejército, con actores identificables y una adecuada contextualización histórica. El término mismo, oligarquía, ha disimulado a veces pobreza conceptual en el análisis y, por ende, debe ser reemplazado por denominaciones más precisas y concretas como "banqueros", "beneficiadores" o "comerciantes exportadores”26. Rafael Guidos Véjar sitúa los orígenes del sistema político del país a inicios de la década de 1930 del pasado siglo, observando que "en esa época se sentaron las bases más permanentes de la actual estructura política del país, sin negar por esto las variaciones especificas que se han producido en la constante rearticulación de los componentes sociales del desarrollo económico, social y político posterior”27. La vinculación entre la clase dominante y el ejército no parece haber sido demasiado estrecha durante las primeras décadas del siglo XX. Guidos Véjar reconoce que "los sectores del capital” se mostraron reacios a aceptar a un cuerpo de oficiales "que se nutría de otras clases distintas a la propietaria", pero que a partir de 1912, año de creación de la Guardia Nacional, la institución militar comenzó a ser aceptada, aunque de manera paulatina, dentro de los círculos de la clase dominante ${ }^{28}$. La clase propietaria otorgó al ejército su apoyo total hasta después de la represión de la rebelión campesina de $1932^{29}$. Guidos Véjar sostiene que a partir de 1931 "la burguesía cafetalera" inició "un repliegue que la alejó del ejercicio directo del poder político" y los militares asumieron el control total del estado ${ }^{30}$. Guidos Véjar intentó responder a interrogantes relacionadas con la irrupción violenta de los militares en la escena política salvadoreña tratando de establecer que tipo de necesidades

25 "La mayoría de las interpretaciones globales sobre el desarrollo histórico salvadoreño fueron realizadas en las décadas de 1960 y 1970 por intelectuales radicales centroamericanos que tenían una tarea revolucionaria prioritaria: determinar, a través del análisis histórico, el grado de madurez alcanzado por el sistema capitalista. En esta forma, según su razonamiento, se podría saber hasta que punto estaban dadas lascondiciones objetivas para la revolución socialista”. Alvarenga, Patricia. Cultura y ética de la violencia. El Salvador 1880-1932. Editorial Universitaria Centroamericana - EDUCA. San José, Costa Rica, 1996. P. 12

26 "The concept of an elite as a single, dominant interest group -self-aware, self-perpetuating, somewhat conspiratorial, committed to incessant class struggle with the masses - is worse than useless. The term 'elite' is itself a thin cloak for conceptual poverty; scholarship demands that it be discarded and replaced by more precise designations like 'sugar planters', 'textile importers' or 'higher clergy'”. Bushnell, David \& Neill Macaulay. The Emergence of Latin America in the Nineteenth Century. Second Edition. Oxford University Press. New York, 1994. P. 54

27 Guidos Véjar, Rafael. Ascenso del militarismo en El Salvador. EDUCA, segunda edición. San José, 1982, p. 9

28 Guidos Véjar, pp. 175-176.

29 Guidos Véjar, p. 197

30 Guidos Véjar, El ascenso..., p. 12 
obligaron al "sector dominante con larga tradición de representación directa a dominar políticamente por intermedio de líderes militares”31. La aparición en el espacio político de un nuevo grupo de poder, las fuerzas armadas, y el surgimiento de nuevas relaciones políticas basadas en la fuerza modificaron los patrones tradicionales de funcionamiento de la sociedad. El golpe militar que derrocó al gobierno del presidente Araujo fue un intento desesperado de "miembros del bloque burgués" de controlar el poder del estado que estaban a punto de perder pero "los militares golpistas reformistas" perdieron el control del golpe y fueron desplazados por "militares representativos de los grupos oligárquicos tradicionales"32. La "fracción burguesa" había sido dominante en la década de 1920 y realizó un intento fallido de cambio del sistema de dominación durante el gobierno de Pío Romero Bosque (1927-1931). La insurrección campesina produjo el repliegue de la fracción burguesa y abrió camino al predominio de la oligarquía que, amenazada directamente, tomó el "control de la arena política y militar”33. En el marco interpretativo de Guidos Véjar los militares carecen totalmente de autonomía y son solamente instrumentos dóciles en manos de las fracciones de la clase dominante. El enfoque instrumentalista de las fuerzas armadas de Guidos Véjar es compartido por buen número de estudiosos del proceso político salvadoreño y centroamericano, entre ellos Edelberto Torres Rivas quien tampoco reconoce la autonomía relativa de la institución militar cuando afirma que "los cafetaleros del país decidieron echar al Dr. Araujo y el 2/XII/1931 los militares ejecutaron la orden, colocando al general Maximiliano Hernández Martínez como nuevo presidente. Es este el primer acto de lo que fue la más extendida república pretoriana en América Latina: Ios militares se quedaron en el gobierno durante medio siglo, desde esa fecha hasta 1979/82"34 (el énfasis es mío). Torres Rivas afirma categóricamente que la oligarquía cafetalera "entrega el poder a los militares" pero conserva su preeminencia económica. En "la más típica de las repúblicas cafetaleras de Centroamérica, El Salvador” la oligarquía cedió el liderazgo político al ejército para "proteger su posición de clase" apoyándose en los servicios prestados por la fuerza militar del estado. En realidad, la intervención de la institución militar en la política salvadoreña no fue el resultado de una decisión abrupta de la oligarquía cafetalera en una coyuntura crítica. El ejército se convirtió paulatinamente en un grupo formidable de presión en

$31 \quad$ Guidos Véjar, p. 14

32 Guidos Véjar, pp. 210-211.

33 Guidos Véjar, p. 211

34 Torres Rivas, La Piel de Centroamérica..., p. 45 
circunstancias que también favorecieron la emergencia de otros grupos en el espacio urbano del país durante la década de 1920. La crisis del liberalismo tradicional, las limitadas oportunidades para la expansión económica, la desilusión de los grupos medios con la política liberal, el descontento de los trabajadores rurales, marginados de los beneficios de la economía de exportación y animados a buscar soluciones radicales a sus problemas fuera del sistema político vigente, y otras circunstancias hicieron inevitable la intervención del estado como árbitro político a través de su institución más poderosa para garantizar la protección de la propiedad y de los intereses de los grupos de poder económico. La elite agraria apoyó al gobierno del general Hernández Martínez hasta después de la derrota del alzamiento campesino de enero de 1932. Antes de dicho acontecimiento, la crisis de legitimidad del gobierno de facto de los militares encabezado por el general Hernández Martínez, “se complicó más aún con la indiferencia de los capitalistas que, lejos de ayudar de manera efectiva al gobierno, daban pábulo con su incomprensión a los agitadores comunistas para atizar la hoguera, que poco tiempo después debía transformarse en una conflagración "35. El alzamiento campesino y su derrota y represión por el ejército validó la presencia de los militares en el gobierno en un contexto en donde "los comerciantes y terratenientes acaudalados no tenían un proyecto político alternativo que ofrecer, pues nunca habían participado extensamente en los asuntos políticos del país; más bien apoyaron la transformación defensiva del estado y las políticas sociales de los nuevos gobernantes militares y sus aliados civiles de los sectores medios urbanos y rurales”36. La militarización del estado salvadoreño fue facilitada por lo que Lauria-Santiago denomina "la privatización del poder en las áreas rurales” sustentada por la dependencia directa de un sector creciente de campesinos, en condición de colonos y arrendatarios, de los grandes terratenientes ${ }^{37}$. Los grandes y medianos terratenientes no decidieron gobernar por medio de un instrumento sin voluntad propia sino que "buscaron en el estado un socio fuerte que haría cumplir los contratos de trabajo y de tierras en el campo y desmovilizaría la participación popular en la política local y nacional”38. LauriaSantiago argumenta que "sería un error insistir en que el café y el cambio en la tenencia de la tierra a finales del siglo fueron las causas estructurales directas del autoritarismo que se erigió

35 Castro Morán, Mariano. Función política del ejército salvadoreño en el presente siglo. UCA Editores.

Tercera Edición. San Salvador, 1989, pp. 91- 92

36 Lauria-Santiago, A. Op.Cit., pp. 346-347

37 Ídem

38 Lauria-Santiago, pp. 346-347 
en la década de 1930, cuando la elite salvadoreña y los sectores medios apoyaron al gobierno militar y la represión posterior en respuesta a las movilizaciones obrero, campesinas de finales de la década de 1920 y el alzamiento revolucionario de 1932"39. El autoritarismo existía en el sistema político salvadoreño antes de la intervención directa de los militares y los cambios derivados de la privatización de las tierras del común, la expansión cafetalera y la formación de un mercado de trabajo asalariado no causaron mecánicamente la emergencia de una nueva forma de autoritarismo expresada en la militarización del estado ${ }^{40}$. La clave del autoritarismo militar en la historia política nacional no reside en la agro exportación cafetalera o en las características de la estructura de la propiedad de la tierra sino que se encuentra en la arena política concebida como un espacio en donde se desarrolla un complejo balance de poder entre el estado y diferentes actores sociales ${ }^{41}$. En un prolongado y discontinuo proceso de institucionalización, las fuerzas armadas desarrollaron su capacidad de proyectar su poder articulando sus intereses a los de otros importantes grupos de la sociedad. Históricamente, la profesionalización militar había sido sumamente irregular en El Salvador. Guidos Véjar observa correctamente que el ejército salvadoreño no constituía "un bloque homogéneo y con un pensamiento unitario" y que no existía dentro del mismo una fracción capaz de influir sobre toda la institución ${ }^{42}$. Circunstancias emergentes favorecieron la cohesión del cuerpo de oficiales, integrado en 1931 por cerca de 300 individuos ${ }^{43}$, alrededor del liderazgo caudillista del general Maximiliano Hernández Martínez. El gobierno del general Hernández Martínez no fue un gobierno de las fuerzas armadas salvadoreñas sino un gobierno de pronunciados rasgos personalistas dominado por un caudillo militar apoyado por un grupo importante de altos oficiales de las fuerzas armadas. En realidad el general Hernández Martínez impidió gobernar directamente a unas fuerzas armadas todavía débilmente profesionalizadas. Al ser obligado a abandonar el poder a mediados de la década de

$39 \quad$ Lauria-Santiago, pp. 349-350

$40 \quad$ Ídem

41 Lauria-Santiago sostiene que después del derrocamiento del presidente Araujo y la derrota de la rebelión de 1932 surgió en El Salvador "un estado autoritario militarizado con profundas conexiones de clientelismo con la elite, los sectores medios del país y los campesinos a nivel local. El nuevo estado se convirtió en el árbitro determinante del desarrollo del país, al establecer una alianza mudable, pero básicamente permanente, con las elites terrateniente y agroexportadora, a la vez que mantenía un equilibrio entre la oligarquía financiera, procesadora y exportadora, y los sectores medios productores de café". Lauria-Santiago, A. Op.Cit., p. 351. En determinadas circunstancias históricas los militares salvadoreños actuaron como una fuerza social y política que excluyó no solamente a sectores medios y populares sino que a la oligarquía misma

42 Guidos Véjar, p. 173

43 Guidos Véjar, p. 176 
1940, los militares salvadoreños se apresuraron a ocupar el vacío de poder dejado por el dictador, reprimieron sin contemplaciones el movimiento urbano de protesta encabezado por representantes de las clases medias de la capital y establecieron su control directo del estado. James Mahoney esboza una interpretación más matizada del problema que la ofrecida por Guidos Véjar y Torres Rivas al subrayar que la amenaza representada por la incorporación de las clases populares del campo a la política nacional no solamente amenazó a la oligarquía cafetalera con una transformación revolucionaria de la economía agraria sino que también provocó el temor de importantes grupos de las clases medias y, en particular, de los oficiales de las fuerzas armadas que expresaron, por lo consiguiente, un interés corporativo propio en derrotar a los campesinos rebeldes y suprimir a los movimientos reformistas democratizadores ${ }^{44}$. El apoyo a los intereses de una oligarquía conservadora no convirtió a los militares salvadoreños en su brazo armado. Dicho apoyo debe interpretarse como una consecuencia de una alianza de beneficio mutuo en la que los militares obtenían ventajas de la gestión directa del estado. Es preciso tener presente que muchos oficiales no eran directamente dependientes de las vinculaciones de tipo político de la cúpula de su institución y que, probablemente, la mayoría de los militares estaban más fuertemente identificados con su institución, una auto-identificación de tipo corporativo, que con cualquier clase social o grupo político fuera de la misma.

\section{LA CONSTITUCIÓN DE LA ELITE DOMINANTE}

El problema de la clase dominante es otro aspecto que merece más atención. La reforma liberal del siglo XIX no fue promovida por una oligarquía radical cohesionada y plenamente constituida ${ }^{45}$. La actuación en el espacio público de grupos de interés de la elite económica bien constituidos fue un acontecimiento relativamente tardío en la historia de El Salvador. Fue hasta finales de la década de 1920 que los grupos de lo que se ha denominado "la oligarquía salvadoreña”, es decir los grupos que controlaban las fases estratégicas de la industria del café: exportadores, banqueros urbanos y un reducido grupo de acaudalados caficultores, comenzaron a promover sus intereses a través de la Asociación Cafetalera creada en 1927. En la década de 1920, grupos de la elite económica que anteriormente actuaban de manera fragmentada formaron alianzas que sustentaron una reestructuración de dicha elite. Los grupos tradicionales originados entre las poderosas familias

$44 \quad$ Mahoney, James. Op.Cit., pp. 126-127

45 Según David Browning, la transición a una economía cafetalera agroexportadora dominada por una oligarquía ocurrió hasta la década de 1920. Citado por Lauria-Santiago, p. 35 
terratenientes decimonónicas, "compartieron su lugar preeminente en el siglo $X X$ con otras familias dedicadas principalmente a la banca, las exportaciones y la administración pública”"46. Nuevos grupos de interés tales como las asociaciones de cafetaleros, azucareros y ganaderos surgieron en la política nacional al mismo tiempo que otros grupos urbanos. A finales de la década de 1920 "la elite era un grupo variado, conformado por viejas familias de terratenientes, aventureros políticos exitosos de las décadas anteriores, comerciantes opulentos, inmigrantes adinerados de reciente presencia y los principales caficultores y cañeros" ${ }^{~}{ }^{7}$. Everett A. Wilson subraya la complejidad y selectividad del proceso de surgimiento de "una clase dominante bien perfilada" en el siglo XX. Circunstancias específicas provocaron un amplio reagrupamiento de la elite económica en el período anterior a 1930 y algunos grupos tuvieron la capacidad de adaptarse a las nuevas oportunidades económicas mientras que otros carecieron de esa habilidad. No todos los grandes terratenientes del país se beneficiaron del boom cafetalero. Hubo muchos hacendados del norte y el oriente del país que perdieron fortuna y status social al permanecer al margen de la expansión cafetalera y sus beneficios. Es importante destacar que el dominio de la elite cafetalera sobre otros grupos sociales se manifestó a través de su control sobre el crédito, el beneficiado y la exportación del café y no del monopolio de la tierra. Miembros poderosos de la elite cafetalera no eran terratenientes productores pero controlaban la producción de café como propietarios de compañías exportadoras y de beneficios. Otros cambios favorecieron también la constitución de una clase dominante capaz de articular sus intereses particulares y proyectarlos en la escena pública. Wilson observa que antes de 1920 la mayoría de las familias prominentes residían en sus propiedades y/o en centros urbanos de los departamentos del país. La "orientación provincial" de las familias de la elite era "persistente" y se reflejaba en "la importancia de los clubes sociales en cada una de las principales ciudades" ${ }^{48}$. Wilson destaca la importancia del traslado de las elites a la capital como un indicador de cambio, derivado del control de la riqueza producida por el café, en el comportamiento económico, social y cultural de dichas elites. Aunque la discreta actividad política de las elites económicas durante la década de 1920 conservó los rasgos personalistas del pasado la presencia de numerosas familias acaudaladas en un mismo espacio urbano, que además era el centro de la actividad política

46 Wilson, Everett Alan. La crisis de la integración nacional en El Salvador, 1919-1935. Biblioteca de

Historia Salvadoreña, volumen No. 17. CONCULTURA. San Salvador, 2004, pp. 81-82

$47 \quad$ Wilson, Everett A. La crisis de la integración..., p. 56

48 Wilson, E.A. Op.Cit., p. 62 
del país, favoreció indudablemente la definición y articulación de sus intereses como grupo lo cual le permitió posteriormente asumir una definida posición política en la esfera pública. La membresía en los clubes de elite, como el Casino Salvadoreño, aumentó como una manifestación de la concentración física de los propietarios de la riqueza del país en la ciudad capital ${ }^{49}$. Es importante destacar que, a medida que crecía la economía agro-exportadora y el proceso de urbanización recibía nuevos impulsos durante la década de 1920, los diferentes sectores sociales perdieron progresivamente su individualismo político tradicional y comenzaron a agruparse en organizaciones de tipo gremial y/o político. Las fuerzas armadas no constituyeron una excepción dentro de dicha tendencia y en 1922 fue fundado el Círculo Militar, institución de inspiración mutualista, como muchas otras asociaciones establecidas en el país en ese período, que además de ofrecer un espacio de sociabilidad, contribuyó indudablemente a cohesionar a la oficialidad del ejército en torno a sus intereses corporativos al proporcionar un espacio efectivo de contacto en el centro político de la república. En la década de 1920 se consuma un redimensionamiento del espacio público que derivó en la definitiva pérdida de importancia de "lo local" como espacio privilegiado de "lo público". La constitución de una escena pública nacional en el centro político de la república es un fenómeno de cardinal importancia propio del siglo XX.

\section{EL MONOPOLIO DE LA VIOLENCIA}

La explicación path-dependence sostiene que el estado liberal del último cuarto del siglo XIX monopolizaba los medios de violencia al contar con una poderosa fuerza militar y este es un postulado que también debe ser objeto de un análisis más cuidadoso. Aldo Lauria-Santiago considera al ejército como "el elemento de continuidad más importante entre las décadas de 1830 y 1930" cuyo "prolongado dominio militar y autoritario de la esfera ejecutiva" tiene su origen en la década de 1830. La tesis de Lauria-Santiago sobre un prolongado patrón de dominio militar presupone, equivocadamente, una continuidad institucional entre la fuerza militar de 1830 y la que sofocó la rebelión campesina en el occidente del país en enero de 1932. El primer problema teórico es la caracterización de las fuerzas militares salvadoreñas de la mayor parte del siglo XIX como un ejército estatal cuando en realidad la organización militar anterior a 1880 recordaba más a las mesnadas medievales ibéricas que a un ejército moderno y los militares se comportaban básicamente como facciones políticas armadas y no como una fuerza profesional.

49 Wilson, pp.120-123 
Los jefes militares del siglo XIX, tal y como lo reconoce Lauria-Santiago, eran, por lo general, más aventureros que militares y participaron exclusivamente en acciones militares de inspiración faccional ${ }^{50}$. Pion -Berlin y Trinkunas llaman la atención sobre la fluidez de los límites entre los políticos civiles y los militares decimonónicos ${ }^{51}$. Los militares salvadoreños del siglo XIX se movían libremente entre las esferas civil y militar debido a que su rol como militares era solamente uno de los múltiples roles que podían asumir. Las escasas biografías de prominentes jefes militares del siglo XIX revelan que los oficiales militares de la época podían alternar su rol militar con otros roles de carácter civil como comerciante, terrateniente, diputado, gobernador, jefe político, etc. Algunos jefes militares prominentes derivaron su fama y fortuna más de sus conexiones familiares, comerciales y políticas que de sus proezas en los campos de batalla. Eric Ching ha puesto de relieve que los militares participaban activamente en el sistema dual de patronato y clientelismo que dominó la política salvadoreña del siglo XIX ${ }^{52}$. La subsiguiente profesionalización de los militares, conducida a veces por militares extranjeros, rompió finalmente el vínculo tradicional entre lo militar y lo civil, alejando definitivamente de la carrera militar a los miembros de la elite económica que anteriormente habían disfrutado de la libre movilidad entre ambas esferas característica del establecimiento militar decimonónico. Los exiguos ingresos gubernamentales impidieron la construcción de fuerzas armadas permanentes desde el período de la emancipación política de la antigua Capitanía General de Guatemala. La única fuerza militar regular heredada de la etapa colonial española fue disuelta por las autoridades federales después de que uno de sus jefes intentara el primer cuartelazo de la historia centroamericana ${ }^{53}$. A

$50 \quad$ La participación de fuerzas militares de los estados centroamericanos en la guerra contra los filibusteros americanos en Nicaragua a inicios de la segunda mitad del siglo XIX constituye un episodio excepcional que confirma la regla.

51 Pion-Berlin, David \& Harold Trinkunas. "Attention Deficits: Why Politicians and Scholars Ignore Defense Policy in Latin America”. 2006 Meeting of the Latin American Studies Association, San Juan, Puerto Rico. Marzo 15-18, 2006

52 "La participación de los militares en política de patronatos marca la diferencia que Rouquié hace entre un ejército social y uno estatal. Un ejército social es un ejército irregular o privado penetrado profundamente por la falta de profesionalismo. Un ejército estatal responde solamente al estado y sirve como su brazo militar. En El Salvador del siglo diecinueve, el ejército era un cuerpo social. Casi cada militar prominente era un hombre de propiedad y riqueza que servía a sus propias redes y no al estado central. En un ambiente político que favorecía a los personajes fuertes, los militares resultaban jugadores naturales de la política. La diferencia entre militares y jefes políticos es difícil de distinguir”. Ching, Eric. "Política y los orígenes del autoritarismo en El Salvador, ca 1840-1940”. Ponencia III Congreso Centroamericano de Historia. San José, Costa Rica, 1996. P. 8

53 El capitán Rafael Ariza Torres se alzó el 14 de septiembre de 1823 contra la autoridad de la Asamblea Nacional Constituyente porque no fue nombrado comandante del Batallón Fijo. "La Asamblea Nacional Constituyente suprimió por decreto el Batallón Fijo a causa de haber sido el alma de la sedición de Ariza, y se 
partir de ese momento las fuerzas militares centroamericanas estuvieron integradas fundamentalmente por milicias campesinas organizadas localmente, única solución viable ante la precaria situación del erario de la Federación. Los esfuerzos por organizar un ejército regular fracasaron por la crónica falta de recursos y la inestabilidad política. La mayoría de los contingentes militares permanentes que los gobiernos salvadoreños del siglo XIX lograron organizar "fueron destruidos o desbandados en conflictos internos o en las guerras con Guatemala y Honduras "54. La transformación de fuerzas militares faccionales en un ejército estatal fue un proceso largo y tortuoso que todavía no ha sido objeto de investigación académica. El ejército en vías de profesionalización del general Gerardo Barrios fue destruido en 1863 por la acción combinada de milicias de campesinos mestizos e indígenas de comunidades desafectas al gobierno que se aliaron a una fuerza militar guatemalteca invasora. De acuerdo con Mahoney, la existencia de un aparato coercitivo centralizado era condición necesaria para la elección de una vía radical de modernización, es decir que los gobernantes liberales pudieron elegir una opción radical de reforma debido a que, supuestamente, disponían de poderosas fuerzas militares. El gobierno que realizó la reforma liberal no contaba, en realidad, con una fuerza militar centralizada capaz de mantener el orden interno y tampoco disponía del monopolio de los medios de violencia organizada. El estado central dependió de milicias ciudadanas, con un fuerte componente indígena, y no de un ejército profesional de línea hasta la década de $1880^{55}$. Las milicias campesinas indígenas de Cojutepeque al mando del general José María Rivas derrotaron en 1885 a 1,200 hombres del supuestamente poderoso ejército del presidente reformista Rafael Zaldívar. El control del occidente del país por los partidarios del general Francisco Menéndez y el triunfo definitivo de la revuelta contra el gobierno de Zaldívar fue posible gracias al pronunciamiento de las milicias indígenas de Nahuizalco dirigidos por su jefe indígena conocido como “General Gutiérrez" ${ }^{56}$. Después del triunfo de la revuelta encabezada por el general Menéndez en junio de 1885, las tropas del general Rivas, aguerridos y bien armados veteranos indígenas de Cojutepeque, constituían una amenaza para el nuevo gobierno por el prestigio ganado en la lucha contra el gobierno de Zaldívar y la influencia ejercida por los enemigos de Menéndez sobre el general

licenció la Compañía de Artillería que estaba en Guatemala por haber participado en aquella revuelta”. Chamorro, Pedro Joaquín. Historia de la Federación de la América Central 1823-1840. Ediciones de Cultura Hispánica.

Madrid, 1951, pp. 100-101

54 Lauria-Santiago, Op.Cit., p. 201

$55 \quad$ Lauria-Santiago, p. 201

56 Vidal, Manuel. Nociones de Historia de Centro América, p. 273 
Rivas. El gobierno retiró al general Rivas de su comando militar y el caudillo de los cojutepeques inició una rebelión que amenazó la capital del país. Tropas gubernamentales a las órdenes del general Carlos Ezeta derrotaron a Rivas en una sangrienta batalla en las alturas de El Mango y Rivas huyó a Honduras. Rivas retornó de Honduras para participar al frente de 3,000 cojutepeques en una guerra contra Guatemala en julio de 1890. Los enemigos del presidente Ezeta persuadieron a Rivas para que se alzara contra el gobierno en lugar de marchar a combatir a los guatemaltecos. Las milicias de Cojutepeque tomaron la capital el 29 de julio después de cruentos combates pero fuerzas militares gubernamentales llegadas apresuradamente del frente derrotaron y ejecutaron a Rivas $^{57}$. La ejecución de Rivas y la derrota definitiva de las milicias indígenas de Cojutepeque deben interpretarse como un importante episodio del proceso de centralización de los medios de violencia por un estado todavía débil pero cada vez menos dependiente de las esferas de poder local. El protagonismo de las milicias campesinas se prolongó hasta el final del siglo XIX a pesar del progreso de la institucionalización de un ejército nacional. Lauria-Santiago indica que "la última transición política importante en la cual se movilizaron campesinos y soldados de las milicias locales, tal como lo habían hecho durante todo el siglo XIX, fue la toma del poder por el general Regalado en 1898"58. Los ingresos de la agro-exportación habían permitido, a partir de la década de 1880, la implementación de programas de reforma militar tendientes a modernizar el ejército, pero el definitivo proceso de institucionalización/profesionalización militar comenzó con el arribo de una misión militar chilena en 1909 y una misión de la Guardia Civil española en $1912^{59}$. La presencia activa de las misiones militares extranjeras no impidió sin embargo que se produjeran retrocesos parciales en los esfuerzos de modernización militar, como cuando el presidente Meléndez "clausuró la academia militar, despidió a la misión chilena y encargó el entrenamiento de la tropa a oficiales de línea "60 con motivo de un par de alzamientos fracasados, el de los cadetes de la academia militar en febrero y el de oficiales del Sexto Regimiento de Infantería en mayo de 1922. A pesar de todo, el proyecto de organización de una fuerza militar profesional técnicamente competente no fue abandonado y el gobierno de Quiñónez fundó una nueva academia militar en agosto de $1927^{61}$. Las asignaciones presupuestarias para las fuerzas

57 Vidal, Manuel. Nociones de Historia de Centro América. (Especial para El Salvador). Sexta edición. Editorial Universitaria. San Salvador, El Salvador, C.A, 1961, pp. 277-278

$58 \quad$ Lauria-Santiago, Op.Cit., p. 199

59 Lauria-Santiago, A. Op.Cit., p. 145

60 Lauria-Santiago, p. 145

61 Lauria-Santiago, p. 146 
armadas aumentaron en la segunda mitad de la década de 1920 y el status de los militares mejoró notablemente durante el gobierno de Pío Romero Bosque. Patricia Alvarenga ha puesto de relieve las dificultades del estado salvadoreño para ejercer el control efectivo del territorio nacional. La Guardia Nacional de El Salvador fue creada por decreto del poder ejecutivo el 3 de febrero de 1912 pero solamente hubo comandancias del nuevo cuerpo en los departamentos que concentraban la mayor parte de la producción cafetalera hasta 1922. Según Alvarenga, no fue sino hasta 1926 que la Guardia Nacional extendió su presencia efectiva a los catorce departamentos de la república ${ }^{62}$. El estado salvadoreño desplegó una política continuada de expansión de las fuerzas de seguridad pública -Guardia Nacional y Policía Urbana- en la década de 1920. La cobertura efectiva del territorio nacional por modernas fuerzas de seguridad no significó, sin embargo, la desaparición del componente civil del aparato de vigilancia. Los antiguos auxilios civiles de las autoridades locales fueron sustituidos por los denominados auxilios militares que, a diferencia de los anteriores, dependían de una institución central del estado: el ejército nacional. La participación de auxiliares civiles en actividades de coerción y vigilancia fue un aspecto de primera importancia en el proceso histórico de construcción del estado salvadoreño. La creación de una extensa red de patrullas civiles integradas por campesinos permitió al estado salvadoreño mantener el campo bajo estricto control hasta la segunda mitad del siglo XX. La dependencia de las fuerzas armadas salvadoreñas de los auxilios civiles ha sido un rasgo persistente de la historia militar y política del país. En Honduras, el relativo aislamiento de los mercados y las redes de poder propició las condiciones para la fragmentación del espacio político y para la pronunciada descentralización del poder político encarnado en caudillos locales y regionales y sus redes de apoyo. Los jefes militares participaban activamente en política de patronato y utilizaban el poder de su red para combatir y derrotar a jefes rivales. Mahoney afirma que los liberales hondureños optaron por una reforma moderada al carecer de un ejército permanente que hubiera posibilitado una opción radical de tipo salvadoreño o guatemalteco. A pesar de la persistencia de un tipo de fuerza militar que ha sido denominado por Ching ${ }^{63}$ ejército "social”, los esfuerzos de los managers del estado por construir, pese al "abortado" reformismo liberal, un ejército "estatal” a finales del siglo XIX han sido a menudo subestimados. La fragmentación política del país no solamente fue el producto de una geografía imposible y de las pugnas entre elites locales sino

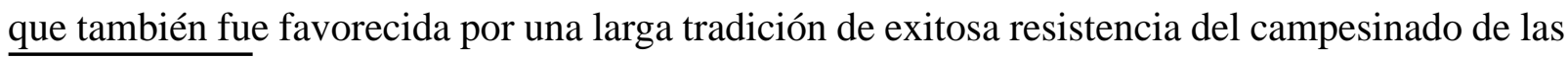
62 Alvarenga, Patricia. Cultura y Ética de la Violencia. El Salvador 1880-1932. EDUCA. 1996, p. 164 63 Ching, Eric, "Política y los orígenes del autoritarismo..., p.8 
tierras altas a los esfuerzos del poder estatal central para colocarlos bajo su autoridad. A pesar de que los sucesores de Soto, exceptuando a Luis Bográn, no continuaron con su programa de reformas $^{64}$, los gobernantes hondureños de finales del siglo XIX intentaron, de acuerdo a los principios liberales introducidos con la reforma de Soto de 1877, monopolizar el uso legítimo de la violencia a través de la institucionalización y profesionalización de una modesta fuerza militar. La formación del estado es un proceso complejo y desigual y la asimetría que puede caracterizarlo se refleja en diferentes ritmos y cualidades en el desarrollo de sus agencias. El ejército hondureño de la última década del siglo XIX estaba más sujeto a un control central, burocrático e impersonal, y menos sujeto a la influencia de los caudillos locales. Existen indicadores que muestran la presencia de características institucionales y profesionales dentro del ejército de la época posterior al fracaso de la reforma liberal. Robert H. Holden analizó la tasa de persistencia de la oficialidad en los escalafones militares hondureños de finales del siglo XIX y concluyó que la estabilidad del cuerpo de oficiales del ejército probablemente haya sido mayor de lo que comúnmente se ha pensado ${ }^{65}$. Holden destaca que "la distribución geográfica de los oficiales, al corresponder a la distribución general de la población, sugiere que existiera un alto nivel de centralización de mando. Si el ejército nacional no fue más que una colección de cuadrillas bajo el mando de varios caudillos regionales, la distribución de oficiales probablemente hubiera sido más aleatoria. En lugar de eso, el patrón distribucional indica la mano de un poder central interesado en ejercer un control efectivo sobre el territorio nacional entero, una meta que requería la dispersión de fuerzas en proporción aproximada a la población”66. La inestabilidad política del país durante las primeras décadas del siglo XX condujo, sin embargo, al fracaso de los esfuerzos por construir una fuerza militar estatal moderna y profesional. El presidente Miguel Dávila (1907-1911) contrató a un militar chileno y a un sargento francés para organizar y dirigir una academia militar y una escuela de artillería respectivamente pero tal experimento no sobrevivió a la revuelta dirigida por Manuel Bonilla en $1911^{67}$. El control de la vida política hondureña por

$64 \quad$ Guevara Escudero, José. Op.Cit., p.222

65 Holden, Robert H. "Caudillos, Partidos, Elecciones y Guerras: hacia un entendimiento de la violencia en la historia política centroamericana”. Tercer Congreso Centroamericano de Historia. San José, Costa Rica, 15-18 de julio de 1996, p. 19

66 Holden, Robert, “Caudillos, Partidos..., pp. 19-20

67 Dodd, Thomas J. Tiburcio Carías. Portrait of a Honduran Political Leader. Louisiana State University Press. Baton Rouge, 2005, p. 94 
un poder ejecutivo central dotado de autoridad total solamente fue posible hasta la década de 1930 bajo la dictadura del general Tiburcio Carías Andino.

\section{CONCLUSIÓN}

A pesar de su poder explicativo el modelo path dependence de James Mahoney calza solamente de manera parcial en el desarrollo histórico centroamericano del período liberal. Los procesos sociopolíticos son el resultado de una compleja interacción entre actores sociales en contextos históricos parcialmente influenciables porla actividad de dichos actores y no deben ser interpretados como resultados derivados de la acción unilateral de las elites o fatalmente determinados por estructuras vacías de la complejidad y de las contingencias propias de la actividad humana. Los principios del liberalismo orientaron reformas concebidas para posibilitar la construcción de una base económica vinculada a los mercados internacionales más importantes e inspiraron leyes que contribuyeron, junto a otros factores diversos, a la creación de instituciones estatales y estructuras sociales perdurables en contextos históricos donde la hibridación de elementos formales e informales produjo inevitablemente una tensión entre una lógica jurídica institucional y la vida cotidiana de las personas.

Heredia, mayo del 2008 